\title{
Longitudinal Distribution of Vascular Resistance in the Pulmonary Arteries, Capillaries, and Veins
}

\author{
Jerome S. Brody, Edward J. Stemmler, and Arthur B. DuBois \\ From the Department of Physiology, Division of Graduate Medicine, University \\ of Pennsylvania School of Medicine, Philadelphia, Pennsylvania 19104
}

A B S T RACT A new method has been described for measuring the pressure and resistance to blood flow in the pulmonary arteries, capillaries, and veins. Studies were performed in dog isolated lung lobes perfused at constant flow with blood from a donor dog. Pulmonary artery and vein volume and total lobar blood volume were measured by the ether plethysmograph and dyedilution techniques. The longitudinal distribution of vascular resistance was determined by analyzing the decrease in perfusion pressure caused by a bolus of low viscosity liquid introduced into the vascular inflow of the lobe.

The pulmonary arteries were responsible for $46 \%$ of total lobar vascular resistance, whereas the pulmonary capillaries and veins accounted for 34 and $20 \%$ of total lobar vascular resistance respectively. Vascular resistance was 322 dynes $\cdot \mathrm{sec} \cdot \mathrm{cm}^{-5} / \mathrm{ml}$ of vessel in the lobar pulmonary arteries, 112 dynes $\cdot \mathrm{sec} \cdot \mathrm{cm}^{-5} / \mathrm{ml}$ in the pulmonary capillaries, and 115 dynes $\cdot \mathrm{sec} \cdot \mathrm{cm}^{-5} / \mathrm{ml}$ in the lobar pulmonary veins. Peak vascular resistivity (resistance per milliliter of volume) was in an area $2 \mathrm{ml}$ proximal to the capillary bed, but resistivity was high throughout the pulmonary arterial tree. The pulmonary arteries accounted for approximately $50 \%$ of vascular resistance upstream from the sluice point when alveolar pressure exceeded venous pressure.

The method described provides the first measurements of pulmonary capillary pressure. Midcapillary pressure averaged $13.3 \mathrm{~cm} \mathrm{H}_{2} \mathrm{O}$, pul-

Dr. Brody is a postdoctoral fellow of the National Institutes of Health.

Received for publication 11 September 1967 and in revised form 4 December 1967. monary artery pressure averaged $20.4 \mathrm{~cm} \mathrm{H}_{2} \mathrm{O}$, and pulmonary vein pressure averaged $9.2 \mathrm{~cm}$ $\mathrm{H}_{2} \mathrm{O}$. These techniques also provide a way of analyzing arterial, capillary, and venous responses to various pharmacologic and physiologic stimuli.

\section{INTRODUCTION}

The arterioles are the major resistance vessels in the systemic vascular bed $(1,2)$, but it is uncertain whether the greatest resistance to blood flow in the lungs is in the arteries, capillaries, or veins $(1,3,4)$.

Piiper (5), in 1958, reasoned from Poiseuille's law that, during constant perfusion, injection into the bloodstream of a bolus of fluid with viscosity different from that of blood would cause a perfusion pressure change proportional to the resistance of the vessels through which the bolus passed. Piiper considered that the major part of vascular resistance was located at one point in the lung, and that the mean appearance time of the viscosity-induced pressure change, multiplied by flow, gave the volume to the "site of main resistance" to blood flow. Piiper, however, did not relate the "site of main resistance" to an anatomic site because he was unable to further subdivide pulmonary vascular volume; furthermore he did not describe the longitudinal distribution of pulmonary vascular resistance.

In the present study the volume to the midpoint of vascular resistance in isolated lung lobes of dogs has been measured by modification of the viscositychange technique described by Piiper. We related the resistance midpoint, $50 \%$ of vascular resistance upstream and $50 \%$ of vascular resistance down- 
stream from this point, to pulmonary artery volume and total blood volume of the lobe during forward perfusion, and to pulmonary vein volume and total blood volume of the lobe during reverse perfusion. The resistance and pressure at intervals along the pulmonary vessels have been calculated by an analysis of the time course of pulmonary artery pressure change recorded as a bolus of low viscosity, $2 \mathrm{ml}$ of saline solution, passed through the vascular bed. This technique provides a way of measuring resistance and pressure throughout the pulmonary vascular bed without requiring direct pressure measurements from multiple points within the lung vessels.

\section{METHODS}

The left basal lobe was exposed through a left lateral thoracic incision in seven 10-14-kg mongrel dogs anesthetized with sodium pentobarbital, $25 \mathrm{mg} / \mathrm{kg}$. The pulmonary arterial and venous vessels and the bronchi to the left upper and middle lobes were isolated, tied, and severed. The left basal lobe artery, vein, and bronchus were isolated and cannulated with polyethylene tubes while we made sure that no air was introduced into the vascular system. The lobe was placed in an airtight box $(17.5 \mathrm{~cm} \times 17.5 \mathrm{~cm} \times 10.0 \mathrm{~cm})$ constructed of 0.25 inch
Plexiglas and was perfused by a constant flow pump with blood drawn from catheters placed in the inferior vena cava and femoral artery of a heparinized donor dog (Fig. 1). Total ischemic time of the lobe was less than $30 \mathrm{~min}$. The donor dogs, weighing 15-25 $\mathrm{kg}$, were anesthetized with sodium pentobarbital, $25 \mathrm{mg} / \mathrm{kg}$, and were allowed to breath spontaneously through a tracheal cannula. The blood from the donor dog was heated to $37^{\circ} \mathrm{C}$, passed through the lobe, collected in a cylindrical venous reservoir, and drained by gravity back into the jugular veins of the same donor dog. The average oxygen pressure $\left(\mathrm{Po}_{2}\right)$ of blood perfusing the lobe was $70 \mathrm{~mm} \mathrm{Hg}$. Average carbon dioxide pressure $\left(\mathrm{PCO}_{2}\right)$ was $38 \mathrm{~mm} \mathrm{Hg}, \mathrm{pH}$ 7.30 .

Differential transducers with one side connected to the plethysmograph were used to measure pulmonary artery, pulmonary vein, and bronchial pressures. Lateral pressures in the pulmonary artery and vein were obtained from side-hole catheters placed just inside the artery and vein and were referred to the height of the center of the lobe. Plethysmograph pressure was monitored by a differential transducer with one side open to the atmosphere. The plethysmograph was calibrated with the lobe in place and the bronchus clamped so that a $1 \mathrm{ml}$ volume change would produce a $25 \mathrm{~mm}$ deflection on the recorder. The lobe was ventilated with room air by a positive pressure pump at a rate of 20 breaths/min with a constant tidal volume that produced transpulmonary pressure of 8-10 $\mathrm{cm} \mathrm{H}_{2} \mathrm{O}$ at peak inspiration. End expiratory pressure was kept constant at $3-5 \mathrm{~cm} \mathrm{H}_{2} \mathrm{O}$.

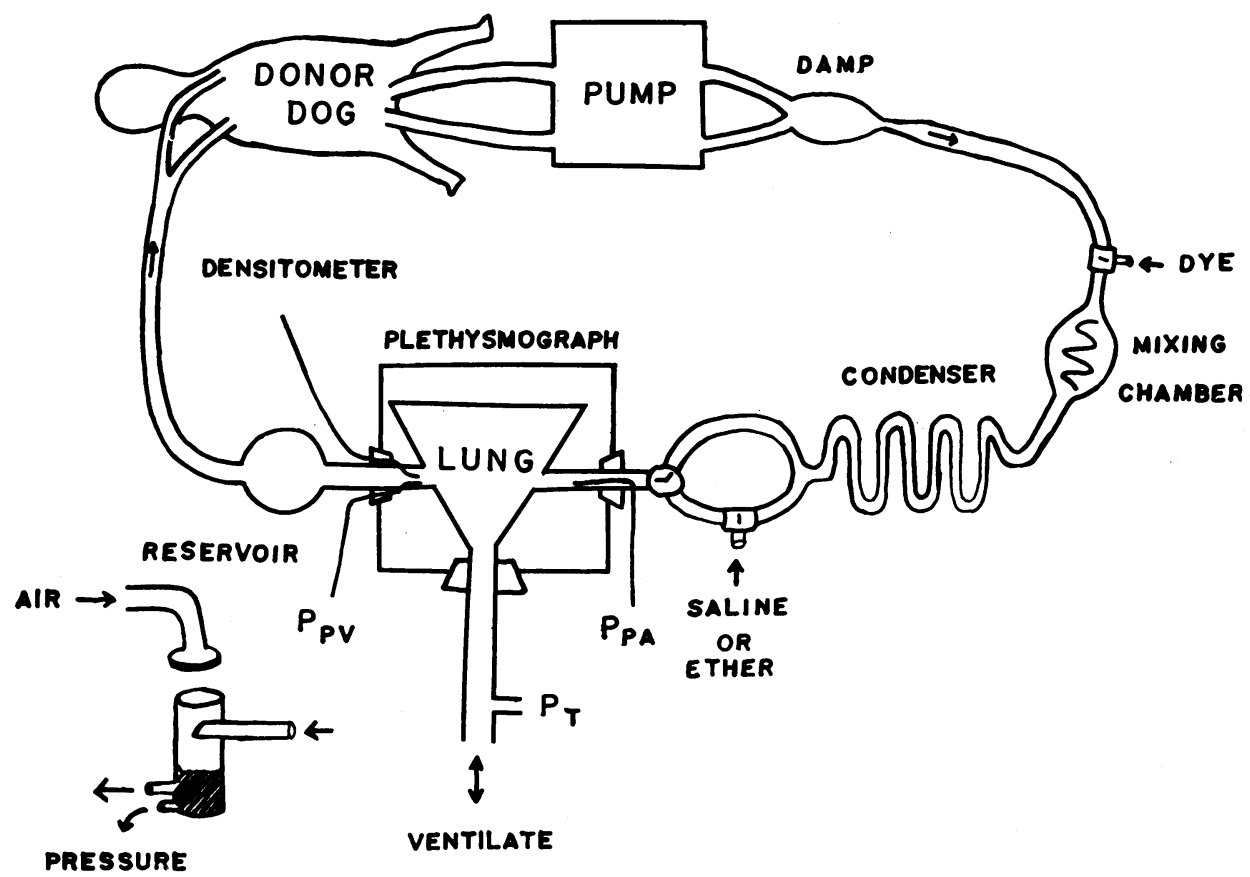

Figure 1 Diagram of experimental setup. Ppv and $P$ pa are lobar pulmonary vein and artery pressures, respectively. $\mathrm{Pt}$ is lobar bronchial pressure. The pulmonary veins may be connected directly to the pump dispensing with the venous reservoir and donor dog if desired. See Methods for explanation. 
The left basal lobe accounts for $25 \%$ of total lung volume in the dog and presumably $25 \%$ of pulmonary blood flow $(6,7)$. Average blood flow through the isolated lobes in seven experiments was $13.6 \mathrm{ml} / \mathrm{min}$ per $\mathrm{kg}$, somewhat less than $20 \%$ of normal cardiac output (8). However, flow at this level has been shown to completely perfuse isolated lung lobes without the appearance of edema (9). Blood flow was measured by occluding the outflow from the venous reservoir and recording the rate of rise of hydrostatic pressure at the bottom of the reservoir. Flow could be measured this way to within $\pm 2 \%$ of flow determined by direct collections in a graduated cylinder. Venous pressure was held constant by making the venous reservoir airtight and submitting it to a constant air pressure of about $9 \mathrm{~cm} \mathrm{H}_{2} \mathrm{O}$. This technique ensured that venous pressure exceeded the alveolar pressures of $3-5 \mathrm{~cm} \mathrm{H}_{2} \mathrm{O}$, and therefore "nonsluice" conditions existed throughout the lobe (10). In four lobes measurements were also made during forward perfusion with the venous reservoir open to the atmosphere and with end expiratory pressure constant at $3-5 \mathrm{~cm}$ $\mathrm{H}_{2} \mathrm{O}$, these being "sluice" conditions (10).

Lobar pulmonary artery and vein pressures, plethysmograph pressure, bronchial pressure, and dye concentrations were recorded on a Grass direct writing instrument. Total lobar blood volume, lobar pulmonary artery volume, and the volume to the midpoint of vascular resistance were each determined in duplicate during short periods of apnea at an end expiratory pressure of $3-5 \mathrm{~cm} \mathrm{H}_{2} \mathrm{O}$ and after a prior inflation of the lobe to about $20 \mathrm{~cm} \mathrm{H}_{2} \mathrm{O}$.

Total lobar blood volume. Total lobar blood volume (VL) was determined by the Stewart-Hamilton indicator dilution method (11) with indocyanine green as the indicator dye. With respiration stopped the dye was flushed into the arterial inflow (Fig. 1) and passed through a mixing chamber before moving into the lung lobe. The concentration of the dye was measured by a Waters XP 250A Densitometer in blood drawn from a catheter placed in the pulmonary vein. The mean appearance time of the dye curve multiplied by flow was the volume of the pulmonary vessels plus the dead space of the tubing. The tubing dead space volume was determined after each experiment, with the lung removed from the apparatus, by the same dye injection technique. The dead space volume was subtracted from the total volume measured during the experiment to give VL. The absolute accuracy and reproducibility of this method were tested with duplicate determinations in tubes of known volume. Tube volumes were measured with no systematic error and with a standard deviation of $0.7 \mathrm{ml}$. The standard deviation between duplicate determinations in the lung lobes was $0.8 \mathrm{ml}$, and the coefficient of variation of duplicates around the mean was $3.5 \%$.

Lobar pulmonary artery volume. Lobar pulmonary artery volume ( $\mathrm{Vpa}$ ) was measured by the technique of Feisal, Soni, and DuBois (12). Ether injected into the pulmonary artery moves from the dissolved state in blood to the gaseous state on contact with alveolar air. A plethysmograph is used to record the rise in alveolar pressure as ether enters the gas phase. Sackner, Feisal, and Karsch (13) calculated that greater than $90 \%$ of the injected ether equilibrates in the first hundredth length of the capillaries. Therefore the ether method measures the vascular volume proximal to the pulmonary capillaries.

$0.20 \mathrm{ml}$ of a $1: 4$ ether-Lipomul solution (12) was placed in one side channel of the perfusion apparatus while all blood was flowing through the opposite symmetrically constructed side channel (Fig. 1). After the plethysmograph had been sealed and respiration of the lobe stopped, a 3-way stopcock was turned diverting all flow through the side channel containing the ether-Lipomul solution, moving the solution into the pulmonary artery. The mean appearance time of the plethysmograph pressure vs. time curve multiplied by flow gave the volume from the site of ether injection to the beginning of the pulmonary capillary bed. The volume of the apparatus dead space between the site of ether injection and the pulmonary artery was measured and subtracted from the volume measured with ether to give Vpa. Because of the small volume of the ether-Lipomul solution $(0.2 \mathrm{ml})$ dispersion of the solution in transit to the end of the pulmonary artery cannula was ignored. A similar method, but with reverse perfusion, was used to measure the volume of the pulmonary veins. The standard deviation of duplicate determinations of $\mathrm{Vpa}$ was $0.2 \mathrm{ml}$. The coefficient of variation of duplicates around the mean was $3.8 \%$.

Volume to the midpoint of lobar vascular resistance. The volume to the midpoint of lobar vascular resistance (Vmp) was measured by a modification of the viscosity change method described by Piiper. The method is based on Poiseuille's law :

$$
\Delta \mathrm{P}=\dot{Q} \times \frac{8}{\pi} \times l / r^{4} \times \eta
$$

This law staates that the pressure drop $(\Delta \mathrm{P})$ across a circular tube during steady laminar flow is equal to the flow in that system ( $\dot{Q})$ multiplied by : a numerical term $(8 / \pi)$ which results from the mathematical analysis of flow in a cylindrical tube; a geometric factor $\left(l / r^{4}\right), l$ being the length of the tube and $r^{4}$ being the radius raised to the fourth power; and the viscosity $(\eta)$ of the fluid perfusing the tube. If all other factors remain constant a change in the viscosity of the perfusate will cause a change of the pressure in the system proportional to the $l / r^{4}$ factor. Laminar flow was present in both lung lobes and model tubes since the Reynold's numbers for the largest pulmonary vessel (diameter equal to the pulmonary artery cannula, $0.4 \mathrm{~cm}$ ) and for all the model tubes were well below the critical number for the occurrence of turbulent flow (14).

$2 \mathrm{ml}$ of $0.9 \% \mathrm{NaCl}$ (saline), warmed to $37^{\circ} \mathrm{C}$, was placed in the perfusion apparatus side channel through which blood was not flowing (Fig. 1). Respiration was stopped, and the 3-way stopcock was turned so that all blood flowed through the channel containing the saline solution, moving the saline into the pulmonary artery. Since flow and venous pressure were constant, the decrease in pulmonary artery pressure was proportional to 
the change in viscosity caused by the saline bolus and to the resistance of the vessels through which the saline was passing. The median appearance time of the curve of pressure decrease vs. time, multiplied by flow, gave the volume from the injection site to the resistance midpoint of the lung. The saline bolus did not appear to alter the resistance of the pulmonary vessels since perfusion pressure returned to the base line after the saline had passed through the lung. In order to determine the effective saline dead space, a saline injection was made without the lobe in place and with a short artificial resistance between the pulmonary artery and pulmonary venous cannulae. The median appearance time of the curve of pressure change vs. time multiplied by flow gave the effective saline dead space which, subtracted from the volume measured with the lung in place, gave the volume to the midpoint of lobar vascular resistance.

Longitudinal distribution of vascular resistance. In order to study the resistance to blood flow at points along the lung vessels rather than just the volume to the midpoint of vascular resistance, the saline-induced pressure curves were analyzed by another method. The abscissa of the pressure curve was marked off in 2-ml increments (flow $\times$ time $=$ volume) beginning with the start of the pressure decrease caused by the saline. These points were equated with volumes at $2-\mathrm{ml}$ intervals along the vascular tree. The pressure decrease at each point was used to calculate vascular resistances for each $2 \mathrm{ml}$ segment.

The pressure change recorded with saline injection is determined by the shape of the saline bolus, i.e. the distribution of viscosity change within the bolus, as well as the distribution of resistances in the system. In order to define the shape of the saline bolus, a short length of tubing with small radius and small volume was substituted for the lung lobe at the end of the pulmonary artery cannula. A bolus of saline was injected during constant blood flow as described above, and the decrease in perfusion pressure was recorded. Because there was virtually no longitudinal distribution of resistance in the small tube, the change in pressure vs. time as the saline bolus passed through the tube was directly proportional to the change in viscosity at each point in volume of the bolus. The

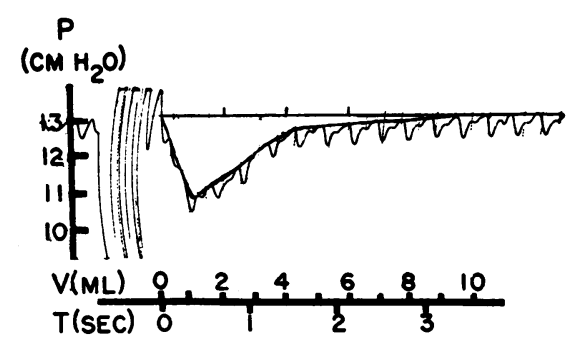

FIgURE 2 Shape of saline bolus. The curve shows the change in perfusion pressure $(P)$ produced as the saline bolus passed through a small volume, high resistance tube which replaced the lung lobe in Fig. 1. The abcissa of the curve is marked at $2-\mathrm{ml}$ volume intervals (flow $X$ time $=$ volume $)$. The viscosity change produced by any portion of the bolus can be calculated from equation 2 . resulting pressure curve (Fig. 2) was a profile of viscosity change vs. volume in the bolus. The pressure curve reflecting the distribution of bolus viscosity change spread through slightly more than $6 \mathrm{ml}$ in volume even though only $2 \mathrm{ml}$ of saline were placed in the side channel. The lengthening of the bolus was probably due to the parabolic front created as blood moved through the channel containing the bolus. Since flow and the length and radius of the resistance tube at the end of the dead space were known, the change in viscosity in each portion of the saline bolus could be calculated :

$$
\Delta \eta \text { saline }=\Delta \mathrm{P} \text { saline } \times \frac{\pi}{8} \times \frac{r^{4}}{l} \times \frac{1}{\bar{Q}} .
$$

In order to simplify the calculations of vascular resistance that follow, the saline bolus was divided into three 2-ml segments. The average decrease in viscosity in the first $2 \mathrm{ml}$ segment was 0.020 poise, that in the second $2 \mathrm{ml}$ segment was 0.010 poise, and that in the third $2 \mathrm{ml} \mathrm{seg-}$ ment was 0.005 poise. The viscosity of the blood was calculated by substituting the pressure drop across the small tube during blood flow for $\Delta \mathrm{P}$ saline in equation 2 . Blood viscosity averaged 0.040 poise. The viscosity of water, at $37^{\circ} \mathrm{C}$, would be 0.0069 poise. These values for blood viscosity and bolus-induced viscosity change were used in all subsequent calculations.

Poiseuille's law is given in equation 1 . If the initial viscosity $\left(\eta_{i}\right)$ of the fluid in a segment of the system is brought to a new level $\left(\eta_{s}\right)$ by a portion of the saline bolus, there is a change in pressure $\left(P_{t}\right)$ to a new level $\left(\mathrm{P}_{s}\right)$. Equation 1 for a segment of the system can be rewritten with $\mathrm{P}_{1}-\mathrm{P}_{s}=\Delta \mathrm{P}_{1}$ saline, and $\eta_{i}-\eta_{s}=\Delta \eta_{1 \text { saline. }}$. $\Delta \mathrm{P}_{1 \text { saline }}$ is the pressure drop in the segment caused by

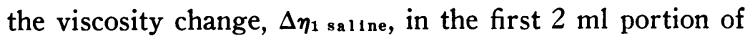
the bolus.

$$
\Delta \mathrm{P}_{1 \text { saline }}=\dot{Q} \times \frac{8}{\pi} \times \frac{l}{r^{4}} \times \Delta \eta_{1 \text { saline }} .
$$

There is no need for absolute pressure or viscosity measurements in segments of the vascular bed since the equations are now in terms of pressure change and viscosity change. By rearranging equation 3 one can solve for the geometric factor characteristic for a segment in the system :

$$
\frac{l}{r^{4}}=\Delta \mathrm{P}_{1 \text { saline }} \times \frac{\pi}{8} \times \frac{1}{\dot{Q}} \times \frac{1}{\Delta \eta}
$$

The pressure decrease recorded as a bolus of low viscosity moves through the lung vessels reflects the resistance of a cross-section of all the vessels in the circulation at a point in volume. The $l / r^{4}$ factor calculated in equation 4 involves not only vessel length and radius but also the number of vascular segments. Since resistances in parallel add by reciprocals, $l / r^{4}=$ (vessel length/ vessel radius*) divided by the number of vascular segments.

Assuming that the geometric factor does not change as the bolus passes through the segment, the resistance $(R)$ of the $2 \mathrm{ml}$ segment with blood flowing through it (vis- 
cosity $\left.=\eta_{\mathrm{blood}}\right)$ can be calculated :

$$
R=8 / \pi \times \frac{l}{r^{4}} \times \eta_{\text {blood }}
$$

The actual pressure drop across that segment can be determined by multiplying $R$ by $\dot{\mathrm{Q}} / 980$.

This analysis is valid for the first $2 \mathrm{ml}$ segment containing the first $2 \mathrm{ml}$ of bolus which causes a viscosity change of 0.020 poise. But as the bolus moves on to the next $2 \mathrm{ml}$ segment, the 0.020 poise viscosity change will move to this segment and the 0.010 poise viscosity decrease of the second portion of the bolus will be in the first $2 \mathrm{ml}$ segment, both segments contributing to the pressure drop measured at the $4 \mathrm{ml}$ point. A correction for the amount of pressure change $\left(\Delta \mathrm{P}_{2 \text { saline }}\right)$ caused by that part of the bolus in the first segment must be made to determine the actual pressure drop and resistance in the second $2 \mathrm{ml}$ portion of the system. This correction can be calculated since the geometric factor for the first $2 \mathrm{ml}$ segment has been calculated, and the change in viscosity $\left(\Delta \eta_{2 s a 11 n e}\right)$ caused by the second portion of the bolus in that segment is known:

$$
\Delta \mathrm{P}_{2 \text { saline }}=\dot{Q} \times{ }_{\pi}^{8} \times \frac{l}{r^{4}} \times \Delta \eta_{2 \text { saline. }}
$$

$\Delta \mathrm{P}_{2 \text { saline }}$ can be subtracted from the total pressure drop at the $4 \mathrm{ml}$ point to give the pressure drop ( $\left.\Delta \mathrm{P}_{1 \text { saline }}\right)$ caused by that part of the bolus in the second $2 \mathrm{ml} \mathrm{seg-}$ ment. The geometric factor and resistance of the second segment can then be calculated as in equations 4 and 5 . A similar correction with a 0.010 decrease in viscosity in the second $2 \mathrm{ml}$ segment and a 0.005 decrease in the first $2 \mathrm{ml}$ segment of the system can be made when the bolus has moved on to the $6 \mathrm{ml}$ mark, and so forth on down the lung lobe.

Fahraeus and Lindquist found that the relative viscosity
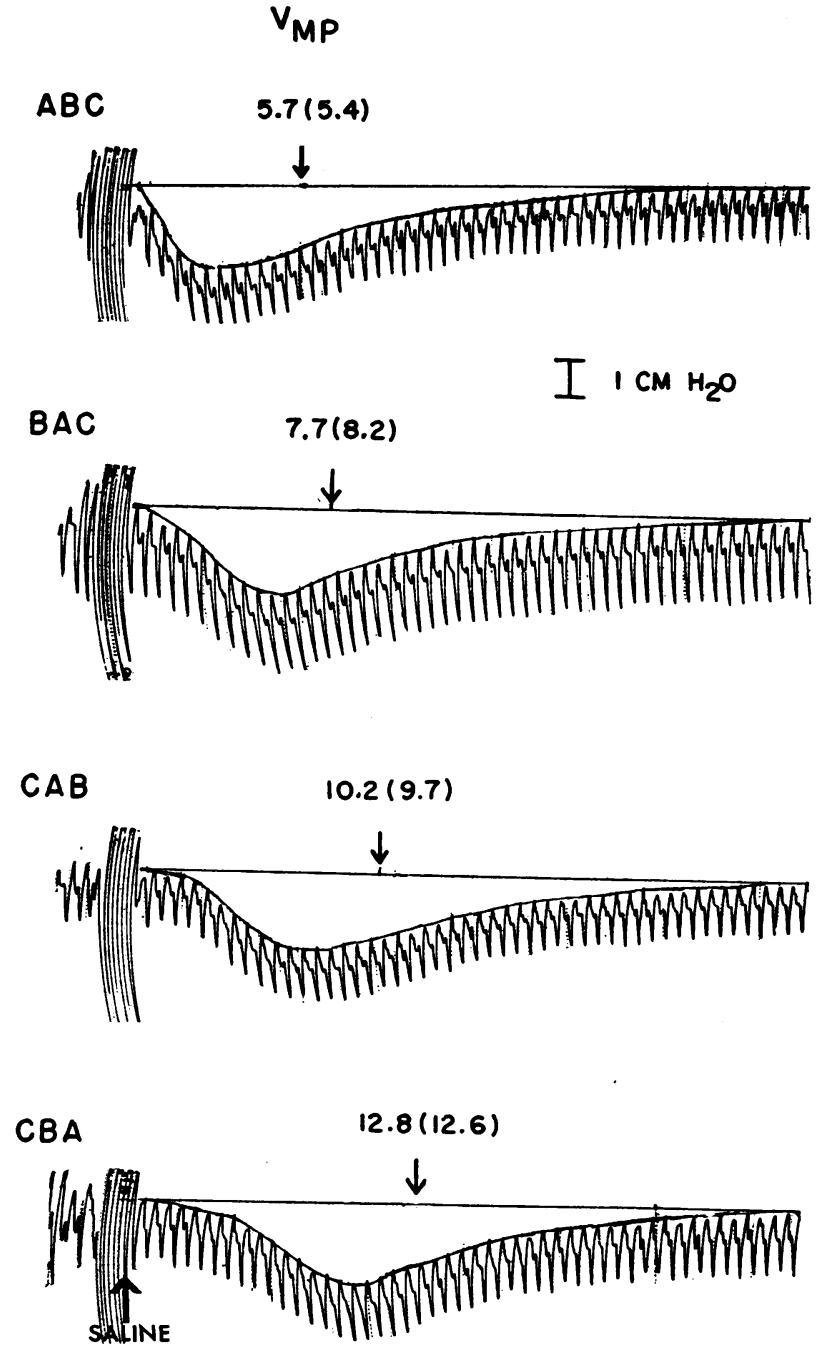

TIME (SEC)
Figure 3 Saline pressure curves from model tubes in series. Resistance of tube A was 3880 dynes $\cdot \mathrm{sec} \cdot \mathrm{cm}^{-5}$, tube B was 1960 dynes $\cdot \mathrm{sec} \cdot \mathrm{cm}^{-5}$, and tube $\mathrm{C}$ was 1090 dynes $\cdot \mathrm{sec} \cdot \mathrm{cm}^{-5} . A B C, B A C$, etc. represent the order in which the tubes were placed. The arrows mark the measured volume to the midpoint of vascular resistance in $\mathrm{ml}$ $(V m p)$. The actual Vmp is in parenthesis. 
of blood decreased in tubes of radius less than $200 \mu$ (15). Relative viscosity in tubes with a radius of $25 \mu$ is approximately one-third less than in tubes with radius larger than $200 \mu$, but it is not clear what the relative viscosity is in vessels as small as the capillaries (16). The decrease in viscosity with the decreasing tube size is present at all hematocrits (16), and therefore $\Delta \eta_{\mathrm{saline}}$ in equations 3 and 4 and $\eta_{b l o o d}$ in equation 5 will decrease by the same proportion. Since $\Delta \eta_{\mathbf{s a l} \text { ine }}$ appears in the denominator of the equations and $\eta_{\mathrm{blood}}$ appears in the numerator, the ratio between the two will remain unchanged in small vessels, and the Fahraeus-Lindquist effect will have little influence on our calculations of resistance.

Total pulmonary vascular resistance was determined by two methods. Resistance determined by summing vascular resistances calculated at 2-ml intervals throughout the lung from passage of a bolus whose viscosity was measured in vitro will be referred to as "calculated resistance." "Measured resistance" was determined by subtracting pulmonary vein pressure from pulmonary artery pressure during nonsluice conditions, or subtracting alveolar pressure from arterial pressure during sluice conditions, multiplying by 980 to convert to dynes per square centimeter and dividing by flow in milliliters per second. Since "calculated resistance" was determined by assuming that blood viscosity was the same in lung vessels of all sizes, the close agreement between "calculated resistance" and "measured resistance" suggests that if there was a lower viscosity in small vessels it was relatively unimportant in our calculations of vascular resistance.

\section{RESULTS}

Model system. The accuracy of the viscositychange method for measuring the volume to the resistance midpoint ( $\mathrm{Vmp}$ ) and the longitudinal distribution of vascular resistance was tested in model tubes of known resistance. The tubes were substituted for the lung lobe in Fig. 1 and were perfused with blood from a reservoir instead of a donor dog.

Three tubes of equal volume but different geometric characteristics can be used to illustrate the significance of the resistance midpoint measurement. Each tube had a volume of $6 \mathrm{ml}$, but at the flow and hematocrit during the experiment the resistance of tube $A$ was 3880 dynes $\cdot \mathrm{sec} \cdot \mathrm{cm}^{-5}$, tube $B$ was 1960 dynes $\cdot \mathrm{sec} \cdot \mathrm{cm}^{-5}$, and tube $\mathrm{C}$ was 1090 dynes $\cdot \mathrm{sec} \cdot \mathrm{cm}^{-5}$. Since the tube volumes were equal, the Vmp for each tube should be and was measured to be the same. The magnitude of the pressure decrease caused by the saline bolus was greatest in the tube with the greatest resistance to blood flow. Fig. 3 shows the pressure tracings after saline injection when the tubes were arranged in series in, several combinations. The contours of the pressure curves differed depending on the order of placement of the tubes. The position of the high resistance tube most affects the shape and the median appearance time of the pressure curves.

The accuracy of the method for measuring volume to the resistance midpoint is demonstrated in Fig. 4, a plot of measured vs. actual Vmp in a variety of single tubes and combinations of tubes. There was no significant difference between actual and measured Vmp. The standard deviation of duplicate determinations of $\mathrm{Vmp}$ in the lung lobes was $0.2 \mathrm{ml}$. The coefficient of variation of duplicates around the mean was $2.6 \%$.

The pressure curves after saline injection in several arrangements of tubes $\mathrm{A}, \mathrm{B}$, and $\mathrm{C}$ were also analyzed to determine the longitudinal distribution of resistance. The resistance per milliliter calculated at $2-\mathrm{ml}$ intervals is compared to actual resistance per milliliter in Fig. 5. There is a good fit of calculated and actual resistances in all but Fig. 5 CBA where the high resistance was downstream. In this situation the downstream resistance is grossly underestimated, whereas the general tendency is to slightly overestimate downstream resistance when it is small.

Table I lists total "calculated resistance," i.e. the sum of the resistances calculated at 2-ml intervals, and the calculated per cent of total resistance in each tube, and compares these to actual values. The results are relatively accurate

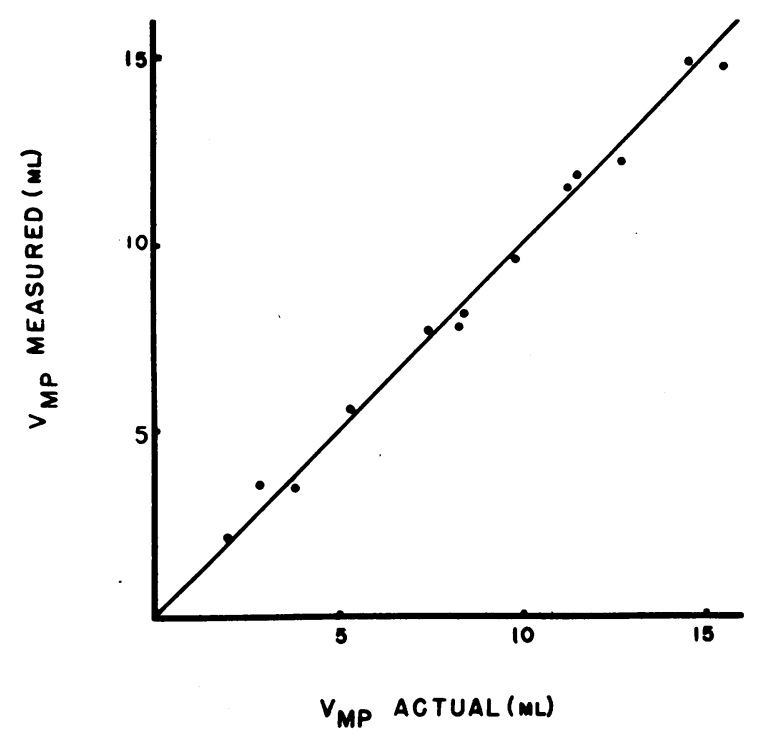

Figure 4 Actual Vmp vs. measured Vmp. Vmp $=$ volume to the midpoint of vascular resistance. 


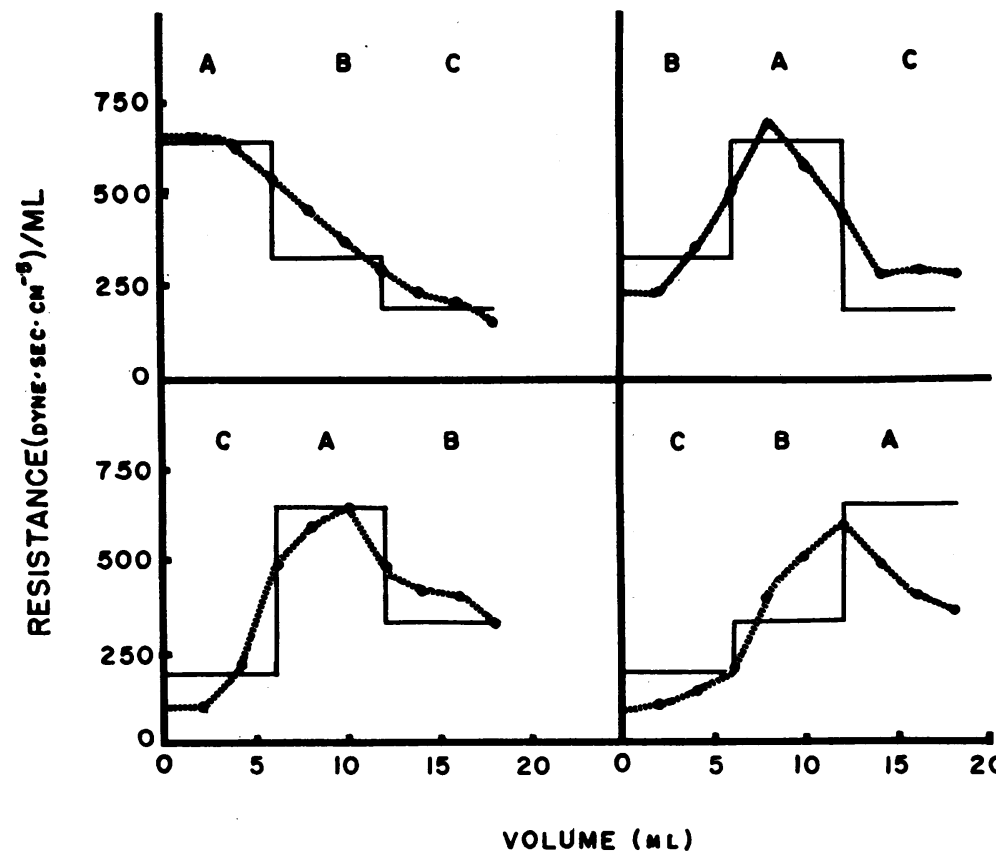

FIGURE 5 Longitudinal distribution of resistance in model tubes in series. Actual (solid line) vs. calculated (interrupted line) resistivity (resistance per milliliter) calculated at 2-ml volume intervals in model tubes $\mathrm{A}, \mathrm{B}$, and $C$ arranged in series.

except in sequence CBA where the large downstream resistance is underestimated. In this case, tube A was calculated to account for $37 \%$ instead of the actual $56 \%$ of total resistance. Although this error affected the calculation of the longitudinal distribution of resistance in CBA, it did not appreciably alter the measurement of the midpoint of vascular resistance, as can be seen in Fig 3 CBA.

Isolated lung lobes. Table II contains a summary of the results of our studies in five isolated lung lobes during forward perfusion and two lung lobes during reverse perfusion in nonsluice conditions, i.e., with downstream pressure $\left(9 \mathrm{~cm} \mathrm{H}_{2} \mathrm{O}\right)$ greater than alveolar pressure $\left(4 \mathrm{~cm} \mathrm{H}_{2} \mathrm{O}\right)$. Average total lobar blood volume (VL) during forward perfusion was $26.6 \mathrm{ml}$. Lobar pulmonary artery volume $(\mathrm{Vpa})$ averaged $6.2 \mathrm{ml}$ or $23 \%$ of VL. During reverse perfusion VL averaged 23.3 $\mathrm{ml}$, and pulmonary vein volume ( $\mathrm{Vpv}$ ) was $6.4 \mathrm{ml}$ or $28 \%$ of VL.

Although forward and reverse perfusion in the lobes were not precisely comparable from the standpoint of pressures applied to artery and vein, and although the studies were done in different lungs, the results of the two experiments can be combined to give a gross estimate of lobar capillary blood volume $(\mathrm{Vpc})$. Since Vpa during forward perfusion $+\mathrm{Vpv}$ during reverse perfusion account for $51 \%$ of VL, Vpc must be $49 \%$ of VL or $12.5 \mathrm{ml}$. The left basal lobe makes up $25 \%$ of total lung volume in dogs and presumably the

TABLE I

Longitudinal Distrabution of Resistance in Model Tubes

\begin{tabular}{|c|c|c|c|c|c|c|c|c|}
\hline \multirow[b]{3}{*}{$\begin{array}{c}\text { Tube } \\
\text { sequence }\end{array}$} & & & \multicolumn{6}{|c|}{ Resistance } \\
\hline & \multicolumn{2}{|c|}{ Resistance } & \multicolumn{2}{|c|}{ Tube A } & \multicolumn{2}{|c|}{ Tube $B$} & \multicolumn{2}{|c|}{ Tube $\mathrm{C}$} \\
\hline & $\begin{array}{l}\text { Calcu- } \\
\text { lated }\end{array}$ & Actual & $\begin{array}{l}\text { Calcu- } \\
\text { lated }\end{array}$ & Actual & $\begin{array}{l}\text { Calcu- } \\
\text { lated }\end{array}$ & Actual & $\begin{array}{l}\text { Calcu- } \\
\text { lated }\end{array}$ & Actual \\
\hline & \multicolumn{2}{|c|}{ dynes $\cdot \mathrm{sec} \cdot \mathrm{cm}^{-5}$} & \multicolumn{2}{|c|}{$\%$ total } & \multicolumn{2}{|c|}{$\%$ total } & \multicolumn{2}{|c|}{$\%$ total } \\
\hline $\mathrm{ABC}$ & 7050 & 6930 & 52 & 56 & 32 & 28 & 16 & 16 \\
\hline BAC & 7390 & 6930 & 47 & 56 & 30 & 28 & 23 & 16 \\
\hline CAB & 6935 & 6930 & 49 & 56 & 30 & 28 & 21 & 16 \\
\hline CBA & 6155 & 6930 & 37 & 56 & 50 & 28 & 13 & 16 \\
\hline
\end{tabular}


TABLE II

Measurements in Lung Lobes under Nonsluice Conditions

\begin{tabular}{|c|c|c|c|c|c|c|c|c|c|c|c|c|c|c|}
\hline Dog & Weight & Flow & $\begin{array}{l}\text { Per- } \\
\text { fusion } \\
\text { pres- } \\
\text { sure }\end{array}$ & $\begin{array}{l}\text { Down- } \\
\text { stream } \\
\text { pres- } \\
\text { sure }\end{array}$ & $\begin{array}{c}\text { Resistance } \\
\text { measured }\end{array}$ & VL & Vpa & Vpc & Vpv & $V m p$ & $\begin{array}{l}\text { Resistance } \\
\text { calculated }\end{array}$ & $\begin{array}{c}\text { Arterial } \\
\text { resistance }\end{array}$ & $\begin{array}{l}\text { Capillary } \\
\text { resistance }\end{array}$ & $\begin{array}{l}\text { Venous } \\
\text { resistance }\end{array}$ \\
\hline & kg & $m l / \min$ & $\mathrm{cm} \mathrm{H}_{2} \mathrm{O}$ & $\mathrm{cm} \mathrm{H}_{2} \mathrm{O}$ & $\begin{array}{c}\text { dynes. } \\
\text { sec } \\
\cdot \mathrm{cm}^{-5}\end{array}$ & $m l$ & $m l$ & $m l$ & $m l$ & $m l$ & $\begin{array}{c}\text { dynes. } \\
\text { sec } \\
\cdot \mathrm{cm}^{-5}\end{array}$ & & \% total resisto & ince \\
\hline \multicolumn{15}{|c|}{ Forward perfusion } \\
\hline A & 11.4 & 143 & 22.0 & 9.5 & 5140 & 24.4 & 7.3 & & & 9.0 & 6405 & 38 & & \\
\hline B & 11.4 & 96 & 18.5 & 8.5 & 6140 & 20.6 & 5.4 & & & 6.1 & 6535 & 48 & & \\
\hline C & 12.3 & 176 & 19.0 & 9.0 & 3340 & 25.3 & 4.9 & & & 5.7 & 2400 & 40 & & \\
\hline D & 11.4 & 176 & 19.0 & 9.0 & 3340 & 28.5 & 6.5 & & & 6.9 & 1970 & 51 & & \\
\hline $\mathrm{E}$ & 13.6 & 214 & 25.0 & 9.5 & 4260 & 34.0 & 6.8 & & & 6.5 & 4745 & 54 & & \\
\hline Mean & 12.1 & 161 & 20.7 & 9.1 & 4446 & 26.6 & 6.2 & $12.8^{*}$ & $7.4^{*}$ & 6.8 & 4375 & 46 & $45^{*}$ & $9 *$ \\
\hline \multicolumn{15}{|c|}{ Reverse perfusion } \\
\hline G & 11.4 & 182 & 19.0 & 9.0 & 3220 & 23.4 & & & 6.7 & 13.6 & 3745 & & & 20 \\
\hline $\mathbf{H}$ & 12.3 & 160 & 20.0 & 10.5 & 3500 & 23.2 & & & 6.1 & 15.0 & 3700 & & & 20 \\
\hline Mean & 11.9 & 171 & 19.5 & 9.8 & 3360 & 23.3 & $5.4 \ddagger$ & $11.5 \ddagger$ & 6.4 & 14.3 & 3725 & $23 \ddagger$ & $57 \ddagger$ & 20 \\
\hline \multicolumn{15}{|c|}{ Mean combined forward and reverse perfusion } \\
\hline & 12.0 & 164 & 20.4 & 9.2 & 4136 & 25.6 & 5.9 & 12.5 & 7.2 & & 4214 & $46 \S$ & $34 \|$ & 20 व \\
\hline
\end{tabular}

VL, total lobar blood volume; Vpa, volume of the pulmonary artery; Vpc, capillary blood volume; Vpv, volume of the pulmonary vein; Vmp. volume to the midpoint of vascular resistance.

* Based on assumption that Vpv is $28 \%$ of VL during forward perfusion.

$\ddagger$ Based on assumption that $\mathrm{Vpa}$ is $23 \%$ of VL during reverse perfusion.

$\$$ From forward perfusion.

$\|$ Remainder.

T From reverse perfusion.

same per cent of total pulmonary blood volume $(6,7)$. Therefore, total capillary blood volume would be $(12.5 \mathrm{ml} \times 100 \%) / 25 \%$, or $50 \mathrm{ml}$ in our dogs. Since pulmonary blood volume in dogs is $11 \mathrm{ml} / \mathrm{kg} \times 100$ (17) our estimated capillary blood volume would be $(50 \mathrm{ml} \div 132 \mathrm{ml}) \times 100$ or
$38 \%$ of total pulmonary blood volume in the dogs used. The difference between lobar capillary blood volume, which was $49 \%$ of lobar blood volume, and total capillary blood volume, which was $38 \%$ of total pulmonary blood volume, can be explained by the presence of the lobar cannulae which ex-
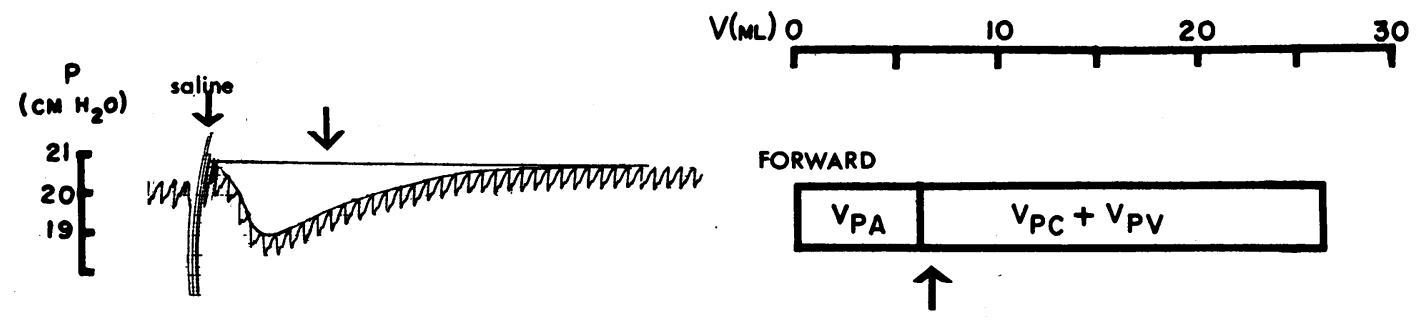

FORWARD
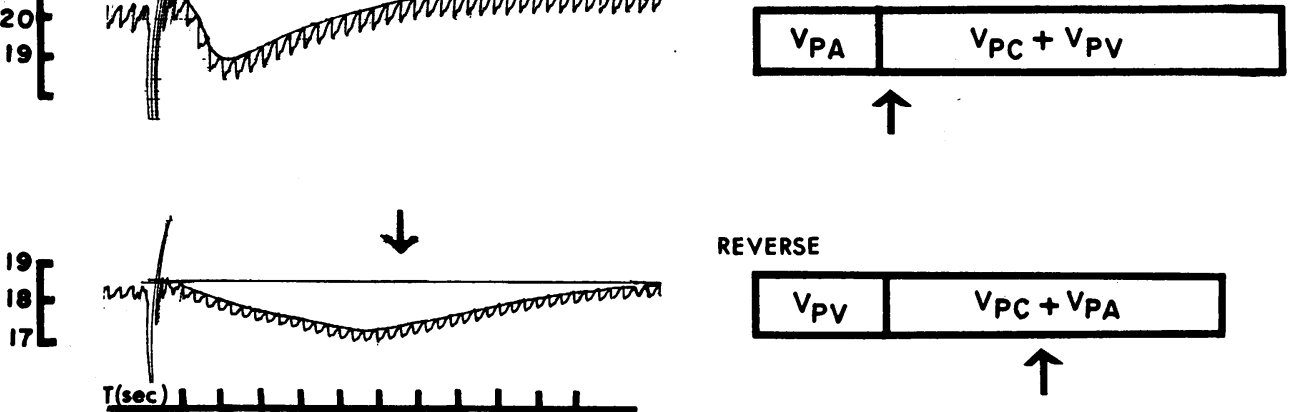

Figure 6 Saline curves in lung lobes. Curves on left show saline-induced pressure curve in one forward perfusion $(\operatorname{dog} C)$ and one reverse perfusion $(\operatorname{dog} G)$ experiment. Vmp is marked with an arrow. Diagram on right represents the average vascular volumes and Vmp in five forward and two reverse perfusion experiments. Vpa, volume of the pulmonary artery; Vpc, capillary blood volume; Vpv, volume of the pulmonary vein. 


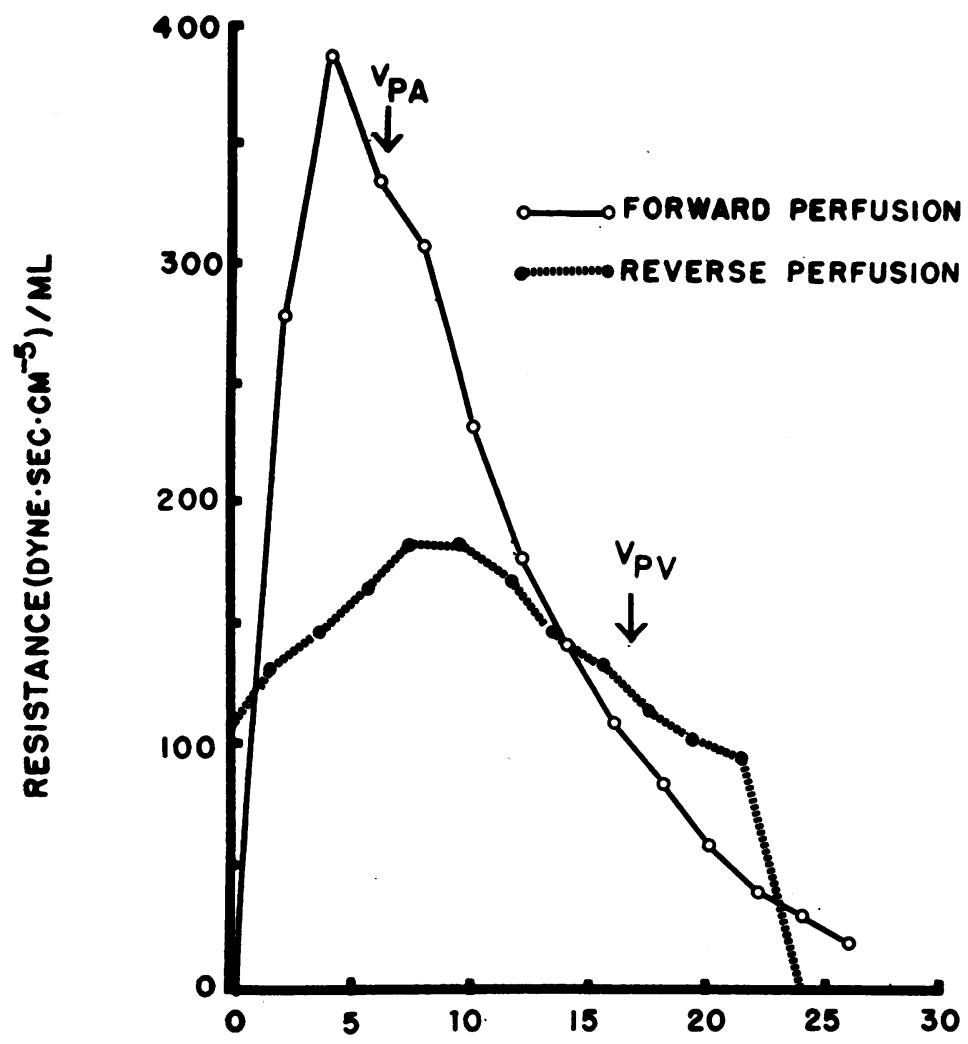

Figure 7 Resistivity in lung lobes. Average resistivity (resistance per milliliter) is calculated at 2-ml intervals in five forward perfusion and two reverse perfusion experiments. Vpa marks the average volume of the pulmonary artery during forward perfusion (reading from left to right). $\mathrm{Vpv}$ marks the average volume of the pulmonary vein during reverse perfusion (reading from right to left).

\section{VOLUME (ML)}

cluded portions of the large conducting arteries and veins in our experiments.

The average volume to the resistance midpoint ( Vmp) during forward perfusion was $6.8 \mathrm{ml}$ or $24 \%$ of VL. Since Vpa averaged $23 \%$ of VL it would appear that the pulmonary artery was responsible for a large portion of total lobar vascular resistance. During reverse perfusion at comparable flow rates Vmp was $14.3 \mathrm{ml}$ or $62 \%$ of VL. Examples of forward and reverse perfusion saline injection curves with $\mathrm{Vmp}$ marked for each are shown in Fig. 6.

Calculation of vascular resistance at $2-\mathrm{ml}$ intervals in the lungs allows a more precise estimate of the vascular resistance of the pulmonary artery and vein. During forward perfusion, lobar pulmonary artery resistance calculated from segmental resistances averaged $46 \%$ of total vascular resistance with a range of $38-54 \%$. If one assumes that $\mathrm{Vpv}$ was $28 \%$ of $\mathrm{VL}$, as measured from reverse perfusion, then lobar venous resistance and lobar capillary resistance during forward perfusion can be subdivided. Lobar venous resistance averaged approximately $9 \%$, and capillary resistance averaged approximately $45 \%$ of total vascular resistance. During reverse perfusion venous resistance accounted for $20 \%$ of total vascular resistance. Arterial resistance was approximately $23 \%$ and capillary resistance approximately $57 \%$ of total vascular resistance. Reverse perfusion of the lobe is analogous to model CBA in Fig. $5 \mathrm{CBA}$ where the high resistance tube was downstream. Calculation of the distribution of resistance was inaccurate distal to the initial low resistance (tube $\mathrm{C}$ in the models or the pulmonary veins in the lungs) in both the models and the lung lobes.

Average "calculated resistance" closely approximated average "measured resistance" in the seven lungs (Table II). However "calculated" and "measured" resistance differed slightly in each individual experiment. In order to compare the results of all the experiments in terms of absolute resistance at $2-\mathrm{ml}$ intervals, the calculated values in each experiment were multiplied by a factor 
which corrected "calculated" to "measured" resistance. This correction did not change the relation between calculated resistances throughout the lobe but rather raised or lowered all values proportionately.

Fig. 7 shows the average resistance per milliliter (resistivity) calculated at 2-ml intervals, for the five forward perfusion and the two reverse perfusion experiments. During forward perfusion vascular resistance was relatively high throughout the pulmonary arterial tree. Resistivity reached a peak slightly before the end of the pulmonary artery and fell throughout the remainder of the pulmonary vascular bed.

The accuracy of the analysis of segmental distribution decreased as the bolus moved downstream (see Discussion), and therefore the resistance of the pulmonary veins was probably estimated more accurately in the reverse perfusion experiments. Since the pulmonary arteries accounted for $46 \%$

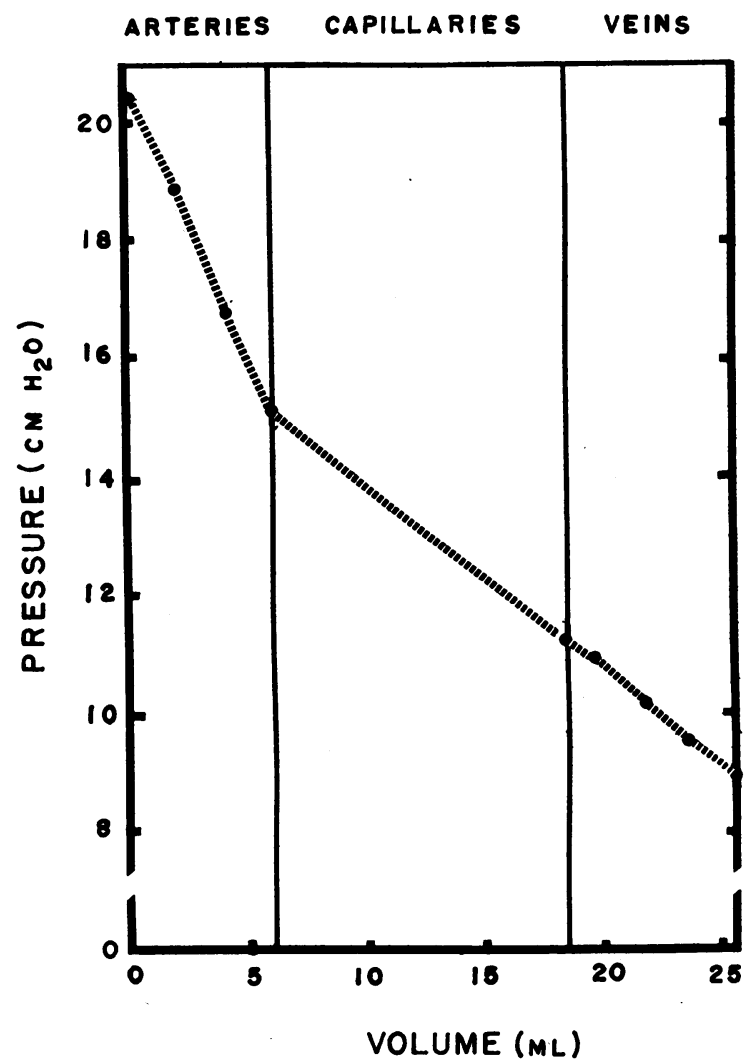

FIGURE 8 Intravascular pressure in lobar vessels. Data for arteries from forward perfusion and data for veins from reverse perfusion.
TABLE III

Measurements in Lung Lobes under Sluice Conditions

\begin{tabular}{|c|c|c|c|c|c|}
\hline Dog & $\begin{array}{l}\text { Perfusion } \\
\text { pressure }\end{array}$ & $\begin{array}{l}\text { Resistance } \\
\text { measured }\end{array}$ & VL & Vpa & Vmp \\
\hline & $\mathrm{cm} \mathrm{H}_{2} \mathrm{O}$ & $\begin{array}{c}\text { dyne } \cdot \mathrm{sec} \\
\mathrm{cm}^{-6}\end{array}$ & $m l$ & $m l$ & $m l$ \\
\hline A & 21.0 & 6740 & 19.2 & 6.5 & 7.5 \\
\hline C & 16.0 & 4000 & 24.4 & 4.7 & 4.8 \\
\hline D & 21.0 & 5660 & 25.5 & 6.1 & 5.8 \\
\hline $\mathrm{E}$ & 23.0 & 4660 & 32.5 & 6.0 & 5.4 \\
\hline Mean & 20.5 & 5265 & 25.4 & 5.8 & 5.7 \\
\hline Mean nonsluice & 21.4 & 4020 & 28.1 & 6.4 & 7.0 \\
\hline Change & +0.9 & -1245 & +2.7 & +0.6 & +1.3 \\
\hline
\end{tabular}

of vascular resistance during forward perfusion and the pulmonary veins for $20 \%$ of total vascular resistance during reverse perfusion, the capillaries would be responsible for approximately $34 \%$ of vascular resistance. Using these figures for the relative distribution of pulmonary vascular resistance, resistance was 322 dynes $\cdot \mathrm{sec} \cdot \mathrm{cm}^{-5} / \mathrm{ml}$ in the pulmonary arteries, 112 dynes $\cdot \mathrm{sec} \cdot \mathrm{cm}^{-5} / \mathrm{ml}$ in the pulmonary capillaries, and 115 dynes.sec $\cdot \mathrm{cm}^{-5} / \mathrm{ml}$ in the pulmonary veins. Fig. 8 shows the average intravascular pressures throughout the pulmonary vascular tree.

Table III shows the data obtained in four lungs during forward perfusion under sluice conditions, i.e., when alveolar pressure exceeded venous pressure. Under these conditions venous resistance was not measured. The resistance midpoint was at the end of the pulmonary artery suggesting that the arteries were responsible for about $50 \%$ of total vascular resistance upstream from the sluice point. On changing to nonsluice conditions by raising venous pressure above alveolar pressure, the resistance midpoint moved downstream away from the pulmonary artery.

\section{DISCUSSION}

Errors in analysis of the distribution of resistances to blood flow. Perfusion pressure decreases during constant blood flow as a bolus of fluid with a viscosity less than that of blood passes through a series of resistances (5). The shape of the curve plotting the decrease in perfusion pressure $(\Delta P)$ against time (or volume) is related to the distribution of resistance in the system and the distribution of viscosity change $(\Delta \eta)$ within the bolus. 
The distribution of resistance along a series of tubes or in the lung can be calculated from the curve of $\Delta \mathrm{P}$ vs. volume if the distribution of viscosity within the bolus is known.

For maximum accuracy the $\Delta \mathrm{P}$ vs. volume curve of the lobe and $\Delta \eta$ vs. volume plot of the bolus should be analyzed continuously or at least at very small volume intervals. The analysis of the $\Delta \mathrm{P}$ vs. volume curve of the lobe was simplified by calculating resistance at 2-ml intervals along the curve. The low viscosity bolus was spread out over a $6 \mathrm{ml}$ volume as it entered the lung. An approximate correction for the shape of the bolus was made by dividing the $\Delta \eta$ volume plot of the bolus into three $2 \mathrm{ml}$ segments. The average $\Delta \eta$ in each segment was used in making the calculations of resistance to blood flow. These simplifications in the calculation of the distribution of vascular resistance tended to decrease slightly the precision of the method in measuring resistance changes occurring over small volume intervals. This decrease is illustrated in Fig. 5 where the actual resistance to flow in model tubes is plotted against resistance calculated from the $\Delta \mathrm{P}$ vs. volume curve resulting from the injection of the low viscosity bolus in the same models. Because the method of analysis did not allow greater precision than $2 \mathrm{ml}$, the exact site of peak resistance to blood flow in the isolated lung lobe could not be placed more closely than $2 \mathrm{ml}$ in a specific anatomic segment of the pulmonary arterial tree.

For the purpose of calculating resistance it was assumed that the distribution of viscosity change within the bolus, i.e. the shape of the bolus, was constant. However, a change in the shape of the bolus did occur as a result of the effects of laminar flow as the bolus passed through the resistance circuit. The front of the bolus moved more rapidly than the body of the bolus, and the tail of the bolus moved at a slower rate than the body of the bolus (14). As a result some viscosity change was present in downstream vessels before it was assumed to be there, and some viscosity change was present in upstream vessels after the bolus had been assumed to have passed through these areas. When downstream resistance was high it was grossly underestimated because the rapidly moving front of the bolus had passed through the high resistance downstream areas and the remainder caused a relatively small pressure drop. The pre- mature passage of the bolus caused an early pressure drop erroneously attributed to the low resistance upstream areas. This phenomenon is illustrated in Fig. $5 \mathrm{CBA}$ and the data recorded during reverse perfusion of the lung lobes.

In general, the further downstream the bolus moved the less compact it was and the less its shape resembled the bolus shape used in the calculations of resistance at 2-ml intervals. In the lungs the problem of bolus distortion was magnified by the multiple parallel channels through which the bolus traveled. Therefore the resistance calculations became less accurate as the bolus moved downstream. For this reason pulmonary artery resistance was most accurate when calculated from the forward perfusion experiments and pulmonary venous resistance most accurate when calculated from the reverse perfusion experiments.

The decrease in perfusion pressure produced by the saline bolus will cause a decrease in the volume of the highly compliant lung vessels. Vascular resistance will increase at the smaller vascular volume abolishing a portion of the salineinduced pressure change. Since the pressure change will be less than it should be, calculated resistance will be underestimated throughout the vascular bed. A method for calculating the approximate degree of underestimation of vascular resistance is described in the Appendix. Arterial resistance was underestimated by about $3 \%$ of its resistance, capillary resistance by $1 \%$, and venous resistance by about $3 \%$. Since resistance was underestimated in all vessels these corrections do not significantly alter the calculated longitudinal distribution of resistance in the lung vessels.

Inherent in the isolated lung lobe preparation used in this study are several conditions which may affect the distribution of pulmonary vascular resistance and limit extrapolation of the present results to the intact animal.

A portion of pulmonary artery and pulmonary vein was excluded from the preparation in the process of cannulating the lobe. As a result "lobar" pulmonary artery and vein volume and "lobar" pulmonary arterial and venous resistance were less than they would be in the whole lung. The resistance to blood flow in the large conducting arteries and veins is not known, but an estimate can be made of the pressure drop across these vessels by using Poiseuille's law. Values for main pulmonary, 
artery, left pulmonary artery, and venous trunk diameter were taken from the measurements of Miller (18), and values for vessel length from the estimates of Schleier (1). At the average flow in our experiments the pressure drop across the main pulmonary artery would be $0.08 \mathrm{~cm} \mathrm{H}_{2} \mathrm{O}$ and the pressure drop across the left pulmonary artery would be $0.12 \mathrm{~cm} \mathrm{H}_{2} \mathrm{O}$. The excluded arteries therefore account for approximately $4 \%$ of total pulmonary artery resistance. The pressure drop across the excluded portion of the pulmonary vein would be $0.05 \mathrm{~cm} \mathrm{H}_{2} \mathrm{O}$ or $2 \%$ of total venous resistance. These corrections do not significantly change the per cent of resistance in each of the vascular beds.

Total vascular resistance of the lung lobes in the present study was similar to or less than that found in other studies of excised and intact lungs at comparable levels of blood flow $(4,19,20)$. The measurements reported were made after perfusion pressure had been constant for 5 min usually 30 $40 \mathrm{~min}$ after the beginning of lobar perfusion. The authors have shown, in the following paper (21), that vascular tone and reactivity are present in both arteries and veins in the isolated lung lobe preparation, and that constriction of either the pulmonary arteries or the pulmonary veins can markedly affect the longitudinal distribution of vascular resistance within the lung. Whether the distribution of vascular resistance in the isolated lung differs from that in the intact lung is not known.

Increasing the pulmonary blood flow or the left atrial pressure has been shown to lower pulmonary vascular resistance $(20,22)$. Kuramoto and Rodbard (23), using catheters placed in the pulmonary artery, small pulmonary veins, and the left atrium to measure pressure gradients across segments of the pulmonary vascular tree, concluded that all vascular segments share equally in the decrease in resistance associated with increasing blood flow. The effect of changing the blood flow on the distribution of segmental vascular resistance was not specifically studied in our preparations. There appears to be no relation between blood flow, which ranged from 96 to $214 \mathrm{ml} / \mathrm{min}$ in the five lungs during forward perfusion, and the per cent of total vascular resistance in the pulmonary arterial or venous vessels.

Pulmonary vein pressure was set, and it aver- aged $9.1 \mathrm{~cm} \mathrm{H}_{2} \mathrm{O}$ during forward perfusion; it was $19.5 \mathrm{~cm} \mathrm{H} \mathrm{H}_{2} \mathrm{O}$ during reverse perfusion. Kuramoto and Rodbard (23) found that pulmonary venous resistance [ (small vein pressure-left atrial pressure)/flow] decreased about $30 \%$ as left atrial pressure was raised from 10 to $20 \mathrm{~cm} \mathrm{H}_{2} \mathrm{O}$. If this correction is applied to the results of the present study, venous resistance would account for $26 \%$ of pulmonary vascular resistance at normal left atrial pressure, rather than the $20 \%$ found at the pressure of reverse perfusion.

End expiratory pressure was kept constant at $3-5 \mathrm{~cm} \mathrm{H} \mathrm{H}_{2} \mathrm{O}$. The lung volume at this transpulmonary pressure corresponds to the volume of air in the lungs at functional residual capacity in the intact animal (24). What effect lung inflation has on arterial, capillary, and venous resistance is not known, although it has been shown that small vessel volume decreases and large vessel volume increases with increasing degrees of lung inflation $(25,26)$.

Longitudinal distribution of pulmonary vascular resistance. The results of the present study indicate that the pulmonary arteries are responsible for an average of $46 \%$ of lobar vascular resistance. The pulmonary capillaries account for $34 \%$ and the pulmonary veins for $20 \%$ of total lobar vascular resistance. Expressed as resistance per milliliter of each vascular bed, arterial resistance is approximately three times capillary or venous resistance. Peak vascular resistivity, i.e. resistance per milliliter, is in an area about $2 \mathrm{ml}$ proximal to the capillary bed, but resistivity is high throughout the pulmonary arterial tree. There does not appear to be a vascular segment in the lung analogous to the high resistance muscular arterioles of the systemic circulation. The pulmonary arteries also contribute about half of vascular resistance upstream from the sluice point when alveolar pressure exceeds venous pressure.

Schleier (1) and more recently Piiper (5, 27) have argued that the capillaries are the major resistance vessels in the lung. Schleier made a detailed mathematical analysis of the distribution of vascular resistance in the human lung using Poiseuille's law. He employed Miller's measurements of vessel diameter (18) and assumed figures for vessel length in his calculations. He concluded that, in contrast to the systemic vascular bed where the muscular arterioles are the major 
resistance vessels, in the lung the capillaries are the major site of vascular resistance.

Schleier's calculated values for resistance actually do not differ greatly from the values measured in the present study. He calculated that the arteries account for $40 \%$ of the total pressure drop across the lung, the capillaries $53 \%$, and the veins $7 \%$ of the total pressure drop across the lung, whereas we calculated that the arteries accounted for $46 \%$, the capillaries $34 \%$, and the veins $20 \%$ of the total pressure drop. The differences between Schleier's figures and ours can be explained by small errors in values used for vessel radius in Schleier's study, and by the fact that he underestimated the cross-sectional area of the capillary bed and therefore overestimated capillary resistance (28).

Piiper (5) in describing the viscosity-change technique for measuring the midpoint of vascular resistance, or as he called it the site of maximal resistance, was unable to place the resistance site in a particular anatomic segment of the pulmonary vascular bed. However, he later concluded that the major portion of vascular resistance in the lung was in the pulmonary capillaries (27). The major difference between Piiper's conclusions and those of the present study lie not in the measurements of the viscosity-induced pressure curve but in the measurement of total lobar blood volume (VL). Piiper used a photomultiplier to measure the transit time of plasma or packed red blood cells through the lung. He found VL to average 1.6 $\mathrm{ml} / \mathrm{kg}$, whereas $\mathrm{VL}$ averaged $2.2 \mathrm{ml} / \mathrm{kg}$ in the present study. The latter figure fits closely with estimated VL based on total pulmonary blood volume being $11 \mathrm{ml} / \mathrm{kg}$ in the $\mathrm{dog}$ (17) and the left basal lobe accounting for $25 \%$ of total lung volume and presumably $25 \%$ of total pulmonary blood volume $(6,7)$. We were unable to measure known volumes accurately using plasma or packed red blood cells as an indicator and a photocell (Grass finger plethysmograph) or photomultiplier as a sensing device. All such measurements grossly underestimated actual volume in our hands probably because the tail of the dilution curve was not visualized. If VL in Piiper's study were increased to that found in the present study his results would agree closely with ours.

There is only one study which suggests that the pulmonary veins are the major resistance ves- sels. Agostoni and Piiper (4) attempted to define midcapillary pressure by measuring the pressure under which Ringer's solution was absorbed by subpleural capillaries. They found that $60 \%$ of vascular resistance in the dog isolated lung lobe was on the venous side of the effective midpoint of the pulmonary capillaries. This is the largest estimate of pulmonary venous resistance in the literature. Whereas the explanation for the difference between these results and the results of the present study is not clear it may be that the subpleural vessels do not reflect true intrapulmonary capillary pressure.

The arguments favoring the pulmonary arteries as the major resistance vessels in the lung have been indirect. Campbell in 1898 (3) reasoned that the large cross-sectional area of the capillary bed offsets the effect of the small capillary vessel size on resistance to blood flow. He concluded that the greatest resistance to blood flow in the lungs was in the pulmonary arterioles. Lawson, Duke, Hyde, and Forster (29) found, by varying blood flow and left atrial pressure in the isolated cat lung, that pulmonary vascular resistance and diffusing capacity could vary independently. This finding suggested to them that the capillary bed was not the major resistance site in the lungs. DeBono and Caro (30) have argued that the relatively rigid smaller pulmonary arteries contribute the major portion of pulmonary vascular resistance during sluice conditions, i.e., when alveolar pressure exceeds venous pressure. As flow increases under these conditions, the relation between flow and pulmonary artery pressure remains linear. This would not be the case if the larger pulmonary arterial vessels which are more compliant contributed a major portion of vascular resistance.

Pulmonary arterial wedge pressure $(\mathrm{Pw})$ provides an approximate measure of venous pressure, but it is not clear which vessels are included in the "arterial" [(Pulmonary artery pressure- $\mathrm{Pw}) /$ flow] and "venous" [( $\mathrm{Pw}$-left atrial pressure $) /$ flow] resistances measured by this method (31). Direct measurements of pressure gradients along pulmonary vessels with small catheters have not provided consistent results in the pulmonary circulation. True lateral pressures are not measured, pressure gradients are small, and variations in pressure with tube placement and tube size and difficulty with catheter wedging have limited con- 
fidence in the results of many of these studies (32, 33 ). "Venous resistance" has ranged from 4 to $20 \%$ of total pulmonary vascular resistance in studies which assume the difference between arterial wedge pressure and left atrial pressure to be the gradient across the pulmonary veins $(34,35)$. "Venous resistance" has ranged from 19 to $49 \%$ of total pulmonary vascular resistance in studies when the difference between pressures recorded from small catheters threaded into pulmonary veins and left atrial pressure was used as the gradient across the pulmonary veins $(36,37)$. Connolly and Wood (38), using the difference between pulmonary artery pressure and pressure recorded from a catheter wedged in the pulmonary veins to estimate the pressure gradient across the pulmonary artery, found "arterial resistance" to be $68 \%$ of total pulmonary vascular resistance in a group of patients. Aviado (37), however, found virtually no pressure gradient across the pulmonary artery in dogs using the wedged venous catheter. No estimates of capillary resistance have been made from any of these studies.

The resistance to blood flow in a vascular bed is determined not only by the length and radius of the vessels in that bed, the $1 / \mathrm{r}^{4}$ factor in Poiseuille's law, but also by the number of vascular segments in the bed. The $l / r^{4}$ factor therefore is multiplied by $1 / n$ where $n$ is the number of vascular segments. Weibel (28) has found capillary length to be $12 \times 10^{-4} \mathrm{~cm}$ and capillary radius $4 \times 10^{-4} \mathrm{~cm}$ in the human lung. But he has also found that there are $280 \times 10^{9}$ capillary segments. The effect of the very small capillary size is therefore cancelled by the large cross-sectional area of the capillary bed. Similar figures for the arterial and venous vessels are not available. It seems probable that the most important determinant of the longitudinal distribution of vascular resistance in the lung is the relation between vessel size (mainly radius) and the total number of segments in a vascular bed.

Pulmonary capillary blood volume. Lobar capillary blood volume ( $\mathrm{Vpc}$ ) was calculated by subtracting lobar pulmonary artery volume, measured in the forward perfusion experiments, plus lobar pulmonary vein volume ( $\mathrm{Vpv}$ ), measured in the reverse perfusion experiments, from total lobar blood volume (VL). Vpc calculated in this way averaged $12.5 \mathrm{ml}$. Total pulmonary capillary blood volume $(\mathrm{Vc})$ was calculated to be $50 \mathrm{ml}$ or $38 \%$ of total pulmonary blood volume. This calculation presumes that $\mathrm{Vpv}$ accounted for the same per cent of VL during forward and reverse perfusion. Some limit can be placed on the error inherent in this assumption. The volume of the capillaries and veins increased by $2.1 \mathrm{ml}$ after elevation of reservoir pressure from 0 to $9 \mathrm{~cm} \mathrm{H}_{2} \mathrm{O}$ during forward perfusion (Table III). Since venous compliance is approximately four times capillary compliance (39), the veins would have increased by $1.7 \mathrm{ml}$. If one assumes that a similar increase in $\mathrm{Vpv}$ would occur if reservoir pressure was raised from 9 to 18 $\mathrm{cm} \mathrm{H}_{2} \mathrm{O}$, the difference in pulmonary vein pressure between forward and reverse perfusion, $\mathrm{Vpv}$ could have been overestimated by a maximum of $1.7 \mathrm{ml}$. Therefore Vpc could not have been more than $14.2 \mathrm{ml}$ nor Vc more than $43 \%$ of total pulmonary blood volume.

Weibel (28) found Vc to average $146 \mathrm{ml}$ in anatomic studies of five human lungs. Bates, Varis, Donevan, and Christie (40) found Vc derived from steady-state diffusing capacity measured during exercise at two different oxygen tensions to average $153 \mathrm{ml}$. Lewis, McElroy, Hayford-Welsing, and Samberg (41) obtained similar values for $\mathrm{Vc}$ in supine man using the rebreathing method for measuring diffusing capacity. If average pulmonary blood volume in man is assumed to be $450-500 \mathrm{ml}(42,43)$, Vc would account for about $30-35 \%$ of total pulmonary blood volume in these studies. Calculation of $\mathrm{Vc}$ derived from single breath diffusing capacity measurements have been somewhat lower both during exercise and in the supine position $(41,44)$. It is difficult to compare the Vc measurements of the present study, those of Weibel (28), Bates and coworkers (40), and Lewis and coworkers (41), which were done at a lung volume equivalent to functional residual capacity with Vc values determined by the single breath-diffusing capacity method which is done at peak inspiration. The relation between degree of lung inflation and pulmonary vascular volume is complex. Macklin (25) and Howell, Permutt, Proctor, and Riley (26) have shown that large and small lung vessels react in different ways to increasing degrees of lung inflation, and Hamer (45) has found that Vc, as measured by single breath-diffusing capacity method, decreases with increasing lung volume. 


\section{Applications}

Vessel response to stimuli. The methods described provide a way of measuring the pressure drop and resistance to blood flow in each portion of the pulmonary or systemic vascular beds without requiring direct measurements of pressure gradients within the vessels. This technique can be applied to analyzing arterial, capillary, and venous responses to a variety of pharmacologic and physiologic stimuli. We report in the following paper (21) the effects of several drugs on the individual vascular segments in the dog lung using the methods described in this paper.

The calculations involved can be simplified and the precision of the results improved if the shape of the low viscosity bolus, the change in bolus shape as it passes through the lung, and the resulting change in perfusion pressure with time in the vessels are analyzed with an analogue or digital computor. The preparation can be simplied as we found by perfusing the lobe of a dog with the dogs own blood and without a donor dog in an open (reservoir) or closed (no reservoir) system. The techniques presumably can also be applied to the intact animal providing that flow and venous pressure are kept constant or measured continuously.

Pulmonary capillary pressure. Accurate measurements of capillary pressure in the systemic circulation have been available for many years (46), but there are no methods for measuring capillary pressure in the lung. The pressure recorded from a catheter wedged into small pulmonary arterial vessels was initially thought to represent pulmonary capillary pressure (47), but further studies have shown that the arterial wedge pressure reflects pressure in vessels distal to the capillary bed (48). Pulmonary venous wedge pressure appears to reflect pressure in vessels proximal to the pulmonary capillaries (48). Agostoni and Piiper (4) described an indirect method for measuring pulmonary capillary pressure from subpleural capillaries, but they admit the subpleural capillary pressure could be quite different from intrapulmonary capillary pressure because of structural differences between the two types of vessels.

Hydrostatic pressure in the pulmonary capillary bed is thought to be the most important factor in the etiology of most forms of pulmonary edema
(49). Investigations into the mechanisms of experimental pulmonary edema have been hampered by the lack of accurate measurements of pulmonary capillary pressure (50). Pulmonary capillary pressure measurements would also be of value in studying the transudation of various substances through the capillary wall and the bursting point of pulmonary capillaries submitted to high transmural pressures such as seen in mitral stenosis or under gravitational stress.

The methods described in the present study allow for the first time accurate measurement of pulmonary capillary pressure. Midcapillary pres sure averaged $13.3 \mathrm{~cm} \mathrm{H} \mathrm{H}_{2} \mathrm{O}$, whereas pulmonary artery pressure averaged $20.4 \mathrm{~cm} \mathrm{H}_{2} \mathrm{O}$, and pulmonary vein pressure averaged $9.2 \mathrm{~cm} \mathrm{H}_{2} \mathrm{O}$. Under the circumstances of the experiments reported, $63 \%$ of the pressure drop in the pulmonary vessels occurred before the midpoint of the pulmonary capillaries. Pressure at the arterial end of the pulmonary capillaries averaged $15.3 \mathrm{~cm} \mathrm{H}_{2} \mathrm{O}$, whereas pressure at the venous end averaged 11.4 $\mathrm{cm} \mathrm{H}_{2} \mathrm{O}$. These values were determined during steady nonpulsatile flow. Linderholm, Kimbel, Lewis, and DuBois' (51) analysis of instantaneous capillary flow and pulse pressure suggests that the pressure-flow curve of the pulmonary vessels is linear. If this is true the longitudinal distribution of resistance determined during nonpulsatile flow should not differ significantly from mean values determined during pulsatile flow.

\section{APPENDIX}

The decrease in perfusion pressure caused by the low viscosity bolus produced a decrease in the volume of the highly compliant lung vessels. During forward perfusion the mean bolus-induced perfusion pressure change averaged $1.3 \mathrm{~cm} \mathrm{H}_{2} \mathrm{O}$ in the pulmonary arteries and $0.8 \mathrm{~cm}$ $\mathrm{H}_{2} \mathrm{O}$ in the pulmonary capillaries. The mean pressure decrease in the pulmonary veins was $0.5 \mathrm{~cm} \mathrm{H} \mathrm{H}_{2} \mathrm{O}$ during reverse perfusion. The vascular volume changes associated with these pressure changes can be estimated by using the values for pulmonary vascular compliance determined by .Engelberg and DuBois (39). Vascular volume decreased $0.2 \mathrm{ml}$ in both the pulmonary arteries and veins and $0.1 \mathrm{ml}$ in the pulmonary capillaries.

The error in the calculations of vascular resistance associated with the vascular volume changes can be derived if it is assumed that vascular conductance is proportional to vascular volume. Point $A$ in Fig. 9 represents the average calculated conductance $\left(\mathrm{G}_{\mathrm{c}}\right)$ for the pulmonary arteries and the average volume at which it was measured [pulmonary artery volume (V) minus the bolus-induced volume changes $(\Delta \mathrm{V})]$. Point $B$ represents 


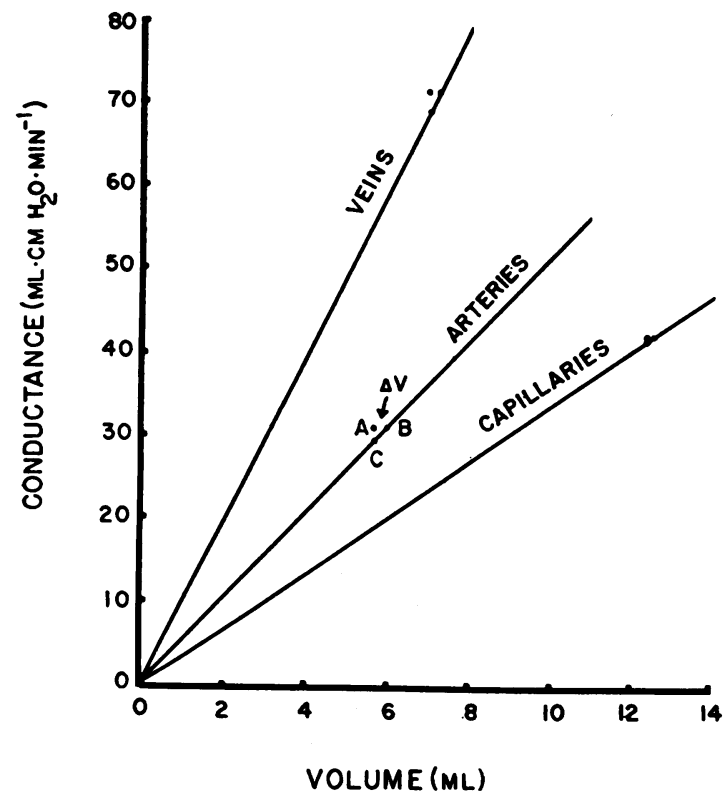

FIGURE 9 Conductance-volume plot of lung vessels. Average conductance values are taken from data in Fig. 8. See Appendix for explanation of abbreviations.

the true volume of the pulmonary arteries. If we assume that the conductance-volume curve of the pulmonary arteries is linear and goes through zero, the slope of the conductance-volume line at point $B$ is $\mathrm{G}_{\mathrm{c}} / \mathrm{V}$. Point $C$ lies on the conductance-volume line and represents the true conductance $\left(G_{t}\right)$ of the pulmonary arteries at the volume $\mathrm{V}-\Delta \mathrm{V}$. The slope of the conductance-volume line through point $C$ is $\mathrm{G}_{\mathrm{t}} /(\mathrm{V}-\Delta \mathrm{V})$. Since the slope of the line through points $B$ and $C$ is the same, the true conductance $\left(G_{t}\right)$ at volume $\mathrm{V}-\Delta \mathrm{V}$ can be determined. $\mathrm{G}_{\mathrm{t}}=$ $\left(\mathrm{G}_{\mathrm{c}} / \mathrm{V}\right) \times(\mathrm{V}-\Delta \mathrm{V})$, and $\mathrm{G}_{\mathrm{c}}, \mathrm{V}$, and $\Delta \mathrm{V}$ are known. $\mathrm{G}_{\mathrm{t}}=(30.7 / 5.9) \times 5.7=29.7 \mathrm{ml} \cdot \mathrm{cm} \mathrm{H} \mathrm{H}_{2} \mathrm{O} \cdot \mathrm{min}^{-1}$. The overestimate of pulmonary artery conductance or underestimate of artery resistance is $\left(\mathrm{G}_{\mathrm{c}}-\mathrm{G}_{\mathrm{t}}\right) / \mathrm{G}_{\mathrm{t}}$ or $3.4 \%$. Similar calculations for the pulmonary capillaries and veins show resistance underestimates of $0.7 \%$ and $2.5 \%$ respectively.

\section{ADDENDUM}

Since this paper was submitted for publication two studies of the distribution of pulmonary vascular resistance have appeared. Garr, Taylor, Owens, and Guyton (52), using an isogravimetric method to estimate pulmonary capillary pressure, found that $56 \%$ of vascular resistance lies before the capillary midpoint in the isolated lung lobe, a result in close agreement with that $(63 \%)$ of the present study. McDonald and Butler (53), employing the vascular waterfall effect, found arterial, capillary, and venous pressure drops to be about equal.

\section{ACKNOWLEDGMENTS}

This work was supported by U. S. Public Health Service grants HE 4797 and HE 7397. Dr. Stemmler received
U. S. Public Health Service Grant 2 T 1-GM-957-05. Dr. DuBois is a recipient of a Research Career Award of the National Institutes of Health.

\section{REFERENCES}

1. Schleier, J. 1918. Der Energieverbrauch in der Blutbahn. Pfleugers Arch. Ges. Physiol. 173: 172.

2. Rushmer, R. F. 1965. The arterial system: arteries and arterioles. In Physiology and Biophysics. T. C. Ruch and H. D. Patton, editors. W. B. Saunders Co., Philadelphia. 19th edition. 600 .

3. Campbell, H. 1898. The resistance to the blood flow. J. Physiol. 23: 301.

4. Agostoni, E., and J. Piiper. 1962. Capillary pressure and distribution of vascular resistance in isolated lung. Am. J. Physiol. 202: 1033.

5. Piiper, J. 1958. Eine Methode zur Lokalisierung des Strömungswiderstandes. Pfleugers Arch. Ges. Physiol. 266: 199.

6. Ferguson, D. J., and R. L. Varco. 1955. The relation of blood pressure and flow to the development and regression of experimentally induced pulmonary arteriosclerosis. Circulation Res. 3: 152.

7. Frank, N. R. 1963. A comparison of static volumepressure relations of excised pulmonary lobes of dogs. J. Appl. Physiol. 18: 274.

8. 1956. Handbook of Biological Data. W. S. Spector, editor. W. B. Saunders Co., Philadelphia. 279.

9. Cross, C. E., P. A. Rieben, and P. F. Salisbury. 1960. Urea permeability of alveolar membrane; hemodynamic effects of liquid in the alveolar spaces. $\mathrm{Am}$. J. Physiol. 198: 1029.

10. Banister, J., and R. W. Torrance. 1960. The effects of tracheal pressure upon flow: pressure relations in the vascular bed of isolated lungs. Quart. J. Exptl. Physiol. 45: 352.

11. Hamilton, W. F., J. W. Moore, J. M. Kinsman, and R. G. Spurling. 1932. Studies on the circulation. IV. Further analysis of the injection method, and of changes in hemodynamics under physiological and pathological conditions. Am. J. Physiol. 99: 534.

12. Feisal, K. A., J. Soni, and A. B. DuBois. 1962. Pulmonary arterial circulation time, pulmonary arterial blood volume, and the ratio of gas to tissue volume in the lungs of dogs. J. Clin. Invest. 41: 390.

13. Sackner, M. A., K. A. Feisal, and D. N. Karsch 1964. Size of gas exchange vessels in the lung. $J$. Clin. Invest. 43: 1847.

14. Burton, A. C. 1965 . Hemodynamics and the physics of the circulation. In Physiology and Biophysics. T. C. Ruch and H. D. Patton, editors. W. B. Saunders Co., Philadelphia. 523.

15. Fahraeus, R., and T. Lindquist. 1931. The viscosity of the blood in narrow capillary tubes. $\mathrm{Am}$. J. Physiol. 96: 562.

16. Haynes, R. H. 1960. Physical basis of the dependence of blood viscosity on tube radius. Am. J. Physiol. 198: 1193 
17. McGaff, C. J., and W. R. Milnor. 1962. Effects of serotonin on pulmonary blood volume in the dog. Am. J. Physiol. 202: 957.

18. Miller, W. S. 1893. The structure of the lung. $J$. Morphol. 8: 165.

19. Williams, M. H., Jr. 1954. Relationships between pulmonary artery pressure and blood flow in the dog lung. Am. J. Physiol. 179: 243.

20. Borst, H. G., M. McGregor, J. L. Whittenberger, and E. Berglund. 1956. Influence of pulmonary arterial and left atrial pressures on pulmonary vascular resistance. Circulation Res. 4: 393.

21. Brody, J. S., and E. J. Stemmler. 1968. Differential reactivity in the pulmonary circulation J. Clin. Invest. 47: 800.

22. Rudolph, A. M., and P. A. M. Auld. 1960. Physical factors affecting normal and serotonin-constricted pulmonary vessels. Am. J. Physiol. 198: 864.

23. Kuramoto, K., and S. Rodbard. 1962. Effects of blood flow and left atrial pressure on pulmonary venous resistance. Circulation Res. 11: 240.

24. Cavagna, G. A., E. J. Stemmler, and A. B. DuBois. 1967. Alveolar resistance to atelectasis. J. Appl. Physiol. 22: 441.

25. Macklin, C. C. 1945. Evidences of increase in the capacity of the pulmonary arteries and veins of dogs, cats, and rabbits during inflation of the freshly excised lung. Rev. Can. Biol. 5: 199.

26. Howell, J. B. L., S. Permutt, D. F. Proctor, and R. L. Riley. 1961. Effect of inflation of the lung on different parts of pulmonary vascular bed. J. Appl. Physiol. 16: 71.

27. Piiper, J. 1960. Die Funktionellen Abschnitte des. Lungengefasssystems. Beitr. Silikose-Forsch. Sonderband. $67: 1$.

28. Weibel, E. R. 1963. Morphometry of the Human Lung. Academic Press Inc., New York. 82.

29. Lawson, W. H., Jr., H. N. Duke, R. W. Hyde, and R. E. Forster. 1964. Relationship of pulmonary arterial and venous pressure to diffusing capacity. J. Appl. Physiol. 19: 381.

30. De Bono, E. F., and C. G. Caro. 1963. Effect of lunginflating pressure on pulmonary blood pressure and flow. Am. J. Physiol. 205: 1178.

31. Burton, A. C. 1953. Peripheral circulation. Ann. Rev. Physiol. 15: 213.

32. Gilbert, R. P., L. B. Hinshaw, H. Kuida, and M. B. Visscher. 1958. Effects of histamine, 5-hydroxytryptamine and epinephrine on pulmonary hemodynamics with particular reference to arterial and venous segment resistances. Am. J. Physiol. 194: 165.

33. Fishman, A. P. 1962. Discussion of paper by A. M. Rudolph. Med. Thorac. 19: 409.

34. Luchsinger, P. C., H. W. Seipp, Jr., and D. L. Patel. 1962. Relationship of pulmonary artery-wedge pressure to left atrial pressure in man. Circulation Res. 11: 315 .

35. Wilcox, B. R., W. G. Austen, and H. W. Bender. 1964. Effects of hypoxia on pulmonary artery pressure of dogs. Am. J. Physiol. 207: 1314.
36. Stern, S., and K. Braun. 1966. Effects of chemoreceptor stimulation on the pulmonary veins. $\mathrm{Am}$. J. Physiol. 210: 535.

37. Aviado, D. M. 1960 . Pulmonary venular responses to anoxia, 5-hydroxytryptamine and histamine. Am. J. Physiol. 198: 1032.

38. Connolly, D. C., and E. H. Wood. 1955. The pulmonary vein wedge pressure in man. Circulation Res. 3: 7 .

39. Engelberg, J., and A. B. DuBois. 1959. Mechanics of pulmonary circulation in isolated rabbit lungs. $\mathrm{Am}$. J. Physiol. 196: 401.

40. Bates, D. V., C. J. Varis, R. E. Donevan, and R. V. Christie. 1960. Variations in the pulmonary capillary blood volume and membrane diffusion component in health and disease. J. Clin. Invest. 39: 1401.

41. Lewis, B. M., W. T. McElroy, E. J. HayfordWelsing, and L. C. Samberg. 1960. The effects of body position, ganglionic blockade and norepinephrine on the pulmonary capillary bed. J. Clin. Invest. 39: 1345.

42. Milnor, W. R., A. D. Jose, and C. J. McGaff. 1960. Pulmonary vascular volume, resistance, and compliance in man. Circulation. 22: 130.

43. Dock, D. S., W. L. Kraus, L. B. McGuire, J. W. Hyland, F. W. Haynes, and L. Dexter. 1961. The pulmonary blood volume in man. J. Clin. Invest. 40: 317.

44. Johnson, R. L., Jr., W. S. Spicer, J. M. Bishop, and R. E. Forster. 1960. Pulmonary capillary blood volume, flow and diffusing capacity during exercise. J. Appl. Physiol. 15: 893.

45. Hamer, N. A. J. 1963. Variations in the components of the diffusing capacity as the lung expands. Clin. Sci. 24: 275.

46. Landis, E. M. 1934. Capillary pressure and capillary permeability. Physiol. Rev. 14: 404.

47. Hellems, H. K., F. W. Haynes, and L. Dexter. 1949. Pulmonary 'capillary' pressure in man. J. Appl. Physiol. 2: 24.

48. Fishman, A. P. 1963. Dynamics of the pulmonary circulation. In Handbook of Physiology. American Physiology Society, Washington, D. C. 2: 1667.

49. Guyton, A. C., and A. W. Lindsey. 1959. Effect of elevated left atrial pressure and decreased plasma protein concentration on the development of pulmonary edema. Circulation Res. 7: 649.

50. Green, D. G. 1965. Pulmonary edema. In Handbook of Physiology. American Physiology Society, Washington, D. C. 2: 1585.

51. Linderholm, H., P. Kimbel, D. H. Lewis, and A. B. DuBois. 1962. Pulmonary capillary blood flow during cardiac catheterization. J. Appl. Physiol. 17: 135.

52. Garr, K. A., Jr., A. E. Taylor, L. H. Owens, and A. C. Guyton. 1967. Pulmonary capillary pressure and filtration coefficient in the isolated perfused lung. $\mathrm{Am}$. J. Physiol. 213: 910.

53. McDonald, I., and J. Butler. 1967. Distribution of vascular resistance in the isolated perfused dog lung. J. Appl. Physiol. 23: 463. 